\title{
Inspiratory Tube Condensation During High-Flow Nasal Cannula Therapy: A Bench Study
}

\author{
Yusuke Chikata PhD, Kazuaki Unai, Masayo Izawa MD, Nao Okuda MD, Jun Oto MD PhD, \\ and Masaji Nishimura MD PhD
}

\begin{abstract}
BACKGROUND: High-flow nasal cannula (HFNC) therapy provides better humidification than conventional oxygen therapy. To allay loss of vapor as condensation, a servo-controlled heating wire is incorporated in the inspiratory tube, but condensation is not completely avoidable. We investigated factors that might affect condensation: thermal characteristics of the inspiratory tube, HFNC flow, and ambient temperature. METHODS: We evaluated 2 types of HFNC tubes, SLH Flex 22-mm single tube and RT202. Both tubes were connected to a heated humidifier with water reservoir. HFNC flow was set at 20, 40, and $60 \mathrm{~L} / \mathrm{min}$, and $\mathrm{F}_{I O}$, was set at 0.21 . Air conditioning was used maintain ambient temperature at close to either 20 or $25^{\circ} \mathrm{C}$. We weighed the tubes on a digital scale before $(0 \mathrm{~h})$ and at 3, 6, and $24 \mathrm{~h}$ after, turning on the heated humidifier, and calculated the amount of condensation by simple subtraction. The amount of distilled water used during $24 \mathrm{~h}$ was also recorded. RESULTS: At $25^{\circ} \mathrm{C}$, there was little condensation, but at $20^{\circ} \mathrm{C}$ and HFNC flow of 20,40 , and $60 \mathrm{~L} / \mathrm{min}$ for $24 \mathrm{~h}$, the amount of condensation with the SLH was $50.2 \pm 10.7,44.3 \pm 17.7$, and $56.6 \pm 13.9 \mathrm{mg}$, and the amount with the RT202 was $96.0 \pm 35.1,72.8 \pm 8.2$, and $64.9 \pm 0.8 \mathrm{mg}$. When ambient temperature was set to $20^{\circ} \mathrm{C}$, condensation with the RT202 was statistically significantly greater than with the SLH at all flow settings $(P<.001)$. CONCLUSIONS: Ambient temperature statistically significantly influenced the amount of condensation in the tubes. Key words: humidification; heated humidifier; absolute humidity; environmental temperature; oxygen therapy. [Respir Care 2016;61(3):300-305. (C) 2016 Daedalus Enterprises]
\end{abstract}

\section{Introduction}

Medical gas is usually supplied cool and dry. If insufficiently conditioned, medical gas may induce bronchoconstriction. ${ }^{1}$ When dry, cold gas is used with conventional oxygen devices, it is associated with mask discomfort, nasal dryness, oral dryness, eye irritation, nasal and eye trauma, gastric distention, and aspiration..$^{2,3}$ By contrast, adequate heating and humidification improve mucociliary function, facilitate secretion clearance, and decrease atel-

\footnotetext{
Dr Chikata is affiliated with the Medical Equipment Center, Tokushima University Hospital, 2-50-1 Kuramoto, Tokushima 770-8503, Japan. Dr Unai is affiliated with the Faculty of Medicine, Tokushima University, 3-18-15 Kuramoto, Tokushima 770-8503, Japan. Drs Izawa and Okuda are affiliated with Emergency and Critical Care Medicine, Tokushima University Hospital, 2-50-1 Kuramoto, Tokushima 770-8503, Japan. Drs Oto and Nishimura are affiliated with Emergency and Critical Care Medicine, Tokushima University Graduate School of Medicine, 3-18-15 Kuramoto, Tokushima 770-8503, Japan.
}

ectasis; this results in a good ventilation/perfusion ratio and oxygenation. ${ }^{4}$ Gas conditioning is also necessary to prevent inspissation of airway secretions, destruction of airway epithelium, and hypothermia.

Administration of high-flow nasal cannula (HFNC) therapy is now commonly used for patients with acute respiratory failure. ${ }^{5} \mathrm{HFNC}$ may deliver up to $60 \mathrm{~L} / \mathrm{min}$ of heated and humidified medical gas to patients via wide-bore nasal prongs. An air/oxygen blender can be set to generate a flow of up to $60 \mathrm{~L} / \mathrm{min}$. This gas is heated and humidified

\footnotetext{
This work was supported by departmental funding. The authors have disclosed no conflicts of interest.

Correspondence: Masaji Nishimura MD PhD, Emergency and Critical Care Medicine, Tokushima University Graduate School of Medicine, 3-18-15 Kuramoto, Tokushima 770-8503, Japan. E-mail: nmasaji@tokushima-u.ac.jp.
}

DOI: $10.4187 /$ respcare. 04331 
with an active humidifier and subsequently delivered through a tube with a heating wire. Although affected by the patient's inspiratory capacity, HFNC is considered to more effectively supply warmth and moisture than other oxygen delivery methods. ${ }^{6}$ During mechanical ventilation, along with the performance of the humidifying devices, the humidification of medical gas is known to be influenced both by ventilator settings and by patient breathing. ${ }^{7-9}$ Other factors that affect humidification during HFNC therapy have hardly been investigated. At high flow, gas remains for only a short time inside the heated humidifier water reservoir and so may not be adequately warmed and humidified. Even when gas is sufficiently warmed and humidified with a heated humidifier, vapor is lost in the inspiratory tube as condensation, which may result in inadequate humidification. In addition, condensation in the tube can lead to other complications; water around the temperature probe may cause the servo control of the heated humidifier to malfunction, and high flow may spit condensation into nostrils and cause discomfort to the patient.

To minimize condensation, it is usual to adjust the temperature settings of the heated humidifier to $37^{\circ} \mathrm{C}$ at the water reservoir outlet and to $40^{\circ} \mathrm{C}$ at the end of the tube. The heating wires inside inspiratory tubes are servo-controlled to maintain the gas inside at a constant temperature. At low gas flow, gas dwells inside the tube for long periods and may be more susceptible to condensation. Although the influence of gas flow on humidification in mechanically ventilated patients is known, ${ }^{5,7}$ the effects have not yet been clarified during HFNC. In a bench study, we investigated the effect of ambient temperature, HFNC flow, and thermal characteristics of the gas delivery tube on tube condensation during HFNC therapy.

\section{Methods}

\section{Experimental Setup}

As Figure 1 shows, via corrugated tube connections, we set up pairs of air/oxygen blenders, water reservoirs (MR290, Fisher \& Paykel, Auckland, New Zealand), and heated humidifiers (MR850, Fisher \& Paykel, Auckland, New Zealand). Downstream from each water reservoir, an HFNC medical gas delivery tube with heating wire was connected to the water reservoir outlet. We used 2 types of HFNC tubes: a 22-mm single tube (SLH, Intersurgical, Berkshire, United Kingdom), and an RT202 (Fisher \& Paykel, Auckland, New Zealand). The SLH tube is enveloped in a plastic sleeve. The heating wire inside each tube was servocontrolled to maintain a set gas temperature at the end of the tube. Nasal prongs (OPT544, Fisher \& Paykel, Auckland, New Zealand) were connected to the end of the tubes. Placed on cradles to keep the tubes and nasal prongs in the air, the SLH and RT202 were juxtaposed. To monitor ambient tem-

\section{QUICK LOOK}

\section{Current knowledge}

A high-flow nasal cannula system is considered to deliver adequately heated and humidified medical gas. It is composed of a heated inspiratory tube to avoid the loss of vapor as condensation. However, there has been little information relating to the formation of condensation during high-flow nasal cannula.

\section{What this paper contributes to our knowledge}

Environmental temperature and types of heating profile of the inspiratory tube are related to the amount of condensation in the tube. As environmental temperature decreases, the amount of condensation in the inspiratory tube increases.

perature, a thermometer (Moiscope, Skynet, Tokyo, Japan) was placed between the SLH and RT202 tubes.

\section{Effect of HFNC Flow and Ambient Temperature on Condensation}

HFNC flow was set at 20, 40, and $60 \mathrm{~L} / \mathrm{min}$. At the outlet of the air/oxygen blender, flow was measured by a pneumotachometer (4700 series, 0-160 L/min, Hans Rudolph, Inc, Shawnee, Kansas) with a differential pressure transducer (TP-602T, $\pm 5 \mathrm{~cm} \mathrm{H}_{2} \mathrm{O}$, Nihon Kohden, Tokyo, Japan). The pneumotachometer was calibrated using a 1.0-L supersyringe. During calibration, the heated humidifier was turned off. The fraction of inspired oxygen was set at 0.21 using an air/oxygen blender (OA2060, San-You Technology, Saitama, Japan).

Before starting the experiment, the inspiratory tube was separated from the water reservoir and prongs, sealed at both ends with a thin, transparent plastic wrap, and weighed on digital scales (NVT1601JP/2, Ohaus, Newark, New Jersey). The temperature settings on the MR 850 were $37^{\circ} \mathrm{C}$ for the reservoir outlet and $40^{\circ} \mathrm{C}$ for the tube end. Before taking measurements, we waited $1 \mathrm{~h}$ for the heated humidifier to stabilize. After 3, 6, and $24 \mathrm{~h}$, the inspiratory tubes were separated from the water reservoir and prongs, and the ends were carefully sealed with plastic wrap to prevent loss of dew from the tube. Each tube was weighed so that the amount of condensation in the tube could be calculated by simple subtraction. After weighing the tubes, the experiment was continued. For each protocol at different settings, measurements were repeated 3 times.

This study was performed in an air-conditioned room in which ambient temperature was set at either 20 or $25^{\circ} \mathrm{C}$. The thermometer was calibrated at these 2 points 


\section{InSPIRATORY Tube CONDENSATION DURING HFNC THERAPY}

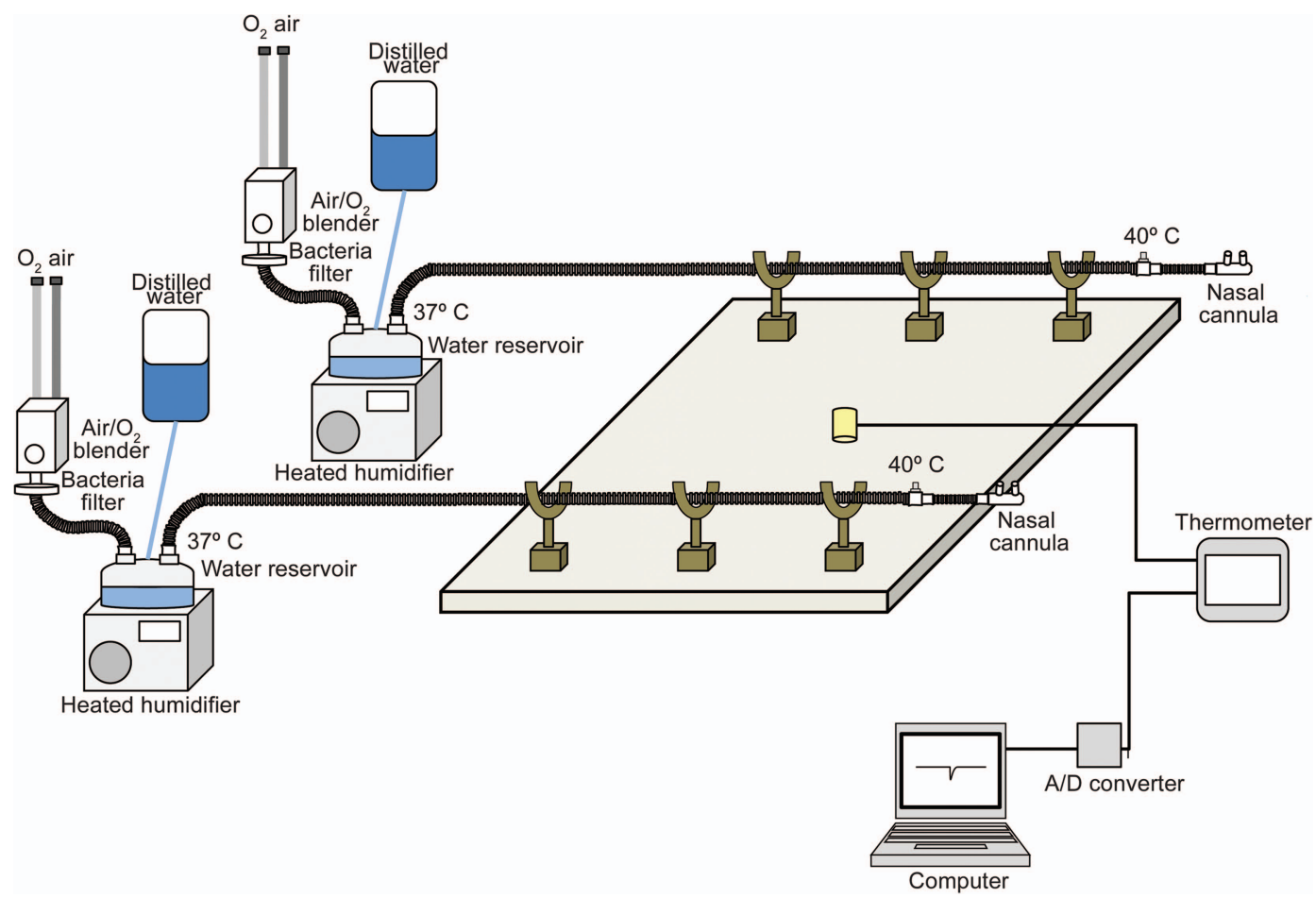

Fig. 1. We tested SLH and RT202 high-flow nasal cannula tubes, both equipped with heating wires. The SLH is enveloped in a plastic sleeve. The 2 high-flow nasal cannula tubes were juxtaposed, and tubes were placed on cradles to keep them in the air. Each tube was connected to the water reservoir outlet of a separated heated humidifier. The heated humidifier parameters were set to $37^{\circ} \mathrm{C}$ at the water reservoir outlet and to $40^{\circ} \mathrm{C}$ at the distal end of the tube. The $\mathrm{F}_{1 \mathrm{O}_{2}}$ setting of the air/oxygen blender was 0.21 . After turning on the heated humidifier, at least $1 \mathrm{~h}$ was allowed for stabilization. Between protocols, the flow meters and heated humidifiers were subject to random crossover. $\mathrm{A} / \mathrm{D}=$ analog/digital.

using a cooler/heater water source (HHC-51, Senko Medical, Tokyo, Japan). The signal was converted using an analog/digital converter (DI-148, Dataq Instruments, Akron, Ohio) and sampled at $10 \mathrm{~Hz} / \mathrm{channel}$ using data acquisition software (WinDaq, Dataq Instruments, Akron, Ohio), and signal data were stored on a computer. At the end of each protocol, randomized crossover of flow meters and heated humidifiers was carried out.

\section{Distilled Water Consumption}

Before and after experimental procedures, the distilled water bag for each heated humidifier was weighed to check total water consumption at $24 \mathrm{~h}$.

\section{Statistics}

The results were expressed as mean $\pm \mathrm{SD}$. Analysis of variance was performed using repeated measures analysis of variance. All statistical tests were 2-sided, and $P<.05$ was considered statistically significant. All statistical analysis was performed using commercial software (SPSS 11.01, SPSS, Chicago, Illinois).

\section{Results}

Measured ambient temperature when room air conditioning was set to $20^{\circ} \mathrm{C}$ was $21.4 \pm 0.8$, and when set to $25^{\circ} \mathrm{C}$, it was $26.1 \pm 0.2^{\circ} \mathrm{C}$.

\section{Condensation}

With ambient temperature set at $20^{\circ} \mathrm{C}$ and HFNC flow at $20 \mathrm{~L} / \mathrm{min}$, after 3,6 , and $24 \mathrm{~h}$, condensation with the SLH was $21.6 \pm 2.0,27.9 \pm 2.6$, and $50.2 \pm 10.7 \mathrm{~g}$, and with the RT202, it was $29.6 \pm 2.1,42.8 \pm 6.1$, and $96.0 \pm 35.1 \mathrm{~g}$. At $40 \mathrm{~L} / \mathrm{min}$, after 3,6 , and $24 \mathrm{~h}$, condensation with the SLH was $20.1 \pm 3.6,28.7 \pm 11.7$, and $44.3 \pm 17.7 \mathrm{~g}$, and with the RT202, it was $34.2 \pm 7.4$, $52.3 \pm 10.4$, and $72.8 \pm 8.2 \mathrm{~g}$. At $60 \mathrm{~L} / \mathrm{min}$, after 3,6 , and $24 \mathrm{~h}$, condensation with the SLH was $17.1 \pm 0.8,24.1 \pm 0.9$, and $56.6 \pm 13.9 \mathrm{~g}$, and with the RT202, it was $28.7 \pm 2.8$, $36.5 \pm 3.8$, and $64.9 \pm 0.8 \mathrm{~g}$.

When ambient temperature was set to $25^{\circ} \mathrm{C}$, condensation was statistically significantly less in all experimental settings than when set to $20^{\circ} \mathrm{C}(P<.001)$ (Fig. 2). At $25^{\circ} \mathrm{C}$, after $24 \mathrm{~h}$, the maximum recorded amount was $<10 \mathrm{~g}$. 

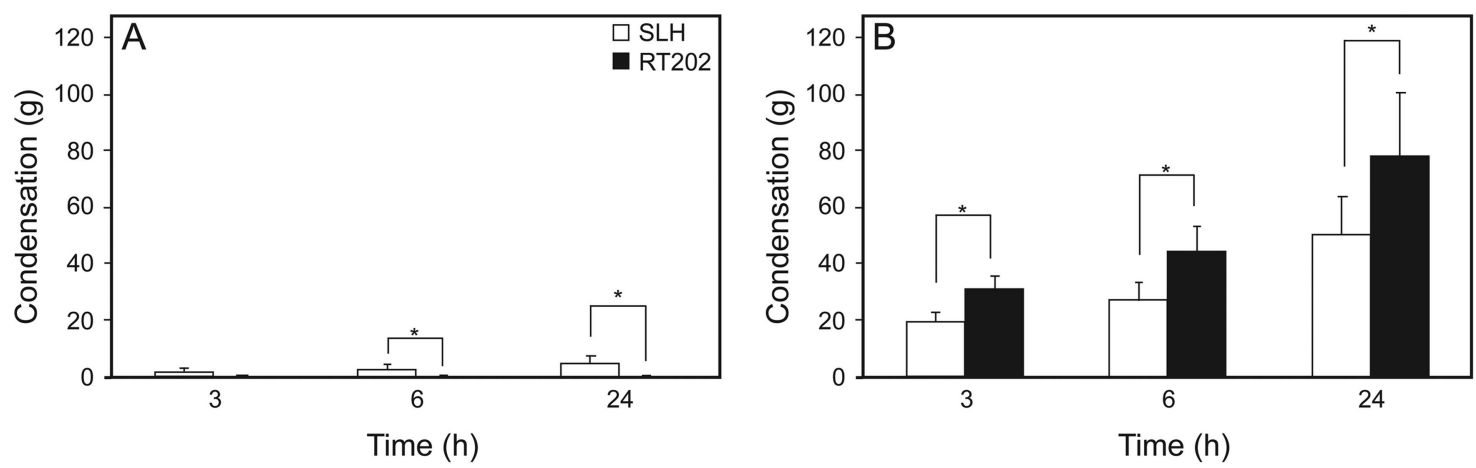

Fig. 2. Amount of condensation measured at 3,6, and $24 \mathrm{~h}$ in both tubes. A: Results when ambient temperature was set at $25^{\circ} \mathrm{C}$. ${ }^{*}, P<$ .05. B: Results when ambient temperature was set at $20^{\circ} \mathrm{C}$. At $25^{\circ} \mathrm{C}$, little condensation occurred in either the SLH or the RT202. At $20^{\circ} \mathrm{C}$, condensation accumulated inside both the SLH and RT202. * $P<.001$.

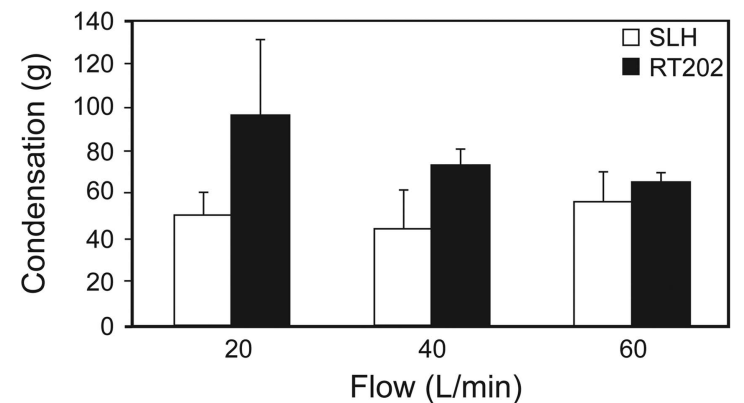

Fig. 3. How different rates of high-flow nasal cannula flow affected the amount of condensation for $24 \mathrm{~h}$ in each tube when ambient temperature was set to $20^{\circ} \mathrm{C}$.

Even so, at the higher ambient temperature setting, at 6 and $24 \mathrm{~h}$, statistically significantly greater amounts of condensation were recorded with the SLH than with the RT202 $(P=.008)$.

With the SLH, condensation was not affected by HFNC flow. With the RT202, as HFNC flow increased, condensation decreased. At $20^{\circ} \mathrm{C}$ in all settings, condensation with the SLH was statistically significantly less than with the RT202 $(P<.001)$ (Fig. 3).

\section{Distilled Water Consumption}

When ambient temperature was set at $20^{\circ} \mathrm{C}$, at $\mathrm{HFNC}$ flow of 20,40 , and $60 \mathrm{~L} / \mathrm{min}$, absolute humidity at the humidifier chamber outlet was $45.8 \pm 0.1,45.5 \pm 0.1$, and $37.8 \pm 0.2 \mathrm{mg} / \mathrm{L}$ with the SLH and $44.2 \pm 0.1,44.6 \pm 0.1$, and $38.0 \pm 0.1 \mathrm{mg} / \mathrm{L}$ with the RT202. When ambient temperature was set at $25^{\circ} \mathrm{C}$, at $\mathrm{HFNC}$ flow of 20,40 , and $60 \mathrm{~L} / \mathrm{min}$, absolute humidity at the humidifier chamber outlet was $44.8 \pm 0.1,44.6 \pm 0.1$, and $39.8 \pm 0.1 \mathrm{mg} / \mathrm{L}$ with the SLH and $44.6 \pm 0.1,44.4 \pm 0.1$, and $41.9 \pm 0.1 \mathrm{mg} / \mathrm{L}$ with the RT202.

Distilled water consumption after $24 \mathrm{~h}$, when ambient temperature was set to $25^{\circ} \mathrm{C}$, at $\mathrm{HFNC}$ flow of 20,40 , and
$60 \mathrm{~L} / \mathrm{min}$ was $1,413.3 \pm 132.3,2,621.5 \pm 111.4$, and $3,593.4 \pm 124.9 \mathrm{~g}$ with the SLH and 1,184.2 \pm 107.8 , $2,362.7 \pm 102.8$, and $3,465.2 \pm 3.2 \mathrm{~g}$ with the RT202; when ambient temperature was set to $20^{\circ} \mathrm{C}$, the figures for the SLH were 1,561.6 $\pm 67.0,3,144.1 \pm 250.5$, and $3,636.2 \pm 224.9 \mathrm{~g}$, and for the RT202, they were $1,436.2 \pm 51.3,2,974.2 \pm 303.7$, and 3,489.8 $\pm 183.6 \mathrm{~g}$. With both HFNC tubes, higher HFNC flow resulted in increased distilled water consumption (Fig. 4).

\section{Discussion}

In the present study, we investigated how ambient temperature, HFNC flow, and thermal characteristics of the inspiratory tube affect condensation in heated-wire gas delivery tubes. The heating wire in each type of tube was servo-controlled to maintain gas temperature and minimize condensation in the tube. In both types, at all experimental settings, statistically significantly more condensation occurred when ambient temperature was set at $20^{\circ} \mathrm{C}$ than when set at $25^{\circ} \mathrm{C}$. A previous study found that the temperature of heated and humidified medical gas in tubes with inner heating wires is influenced by ambient temperature. ${ }^{6}$ Since the tube wall is cooled by ambient air, inner surface condensation may occur, even with servo-controlled temperature function. The greater the internal and external temperature differences are, the more likely condensation will occur inside the tube. Consequently, ambient temperature may be an important factor affecting condensation in gas delivery tubes.

When ambient temperature was set to $20^{\circ} \mathrm{C}$, as HFNC flow increased, condensation decreased in the RT202. Chikata et $\mathrm{a}^{6}$ have reported that as HFNC flow increases, so does the absolute humidity of inspired gas. This is probably because high gas flow reduces the time that medical gas remains in the tube; consequently, medical gas has less contact with the inner surface of the tube and so is less cooled. Less water vapor in the humidified gas is lost to 

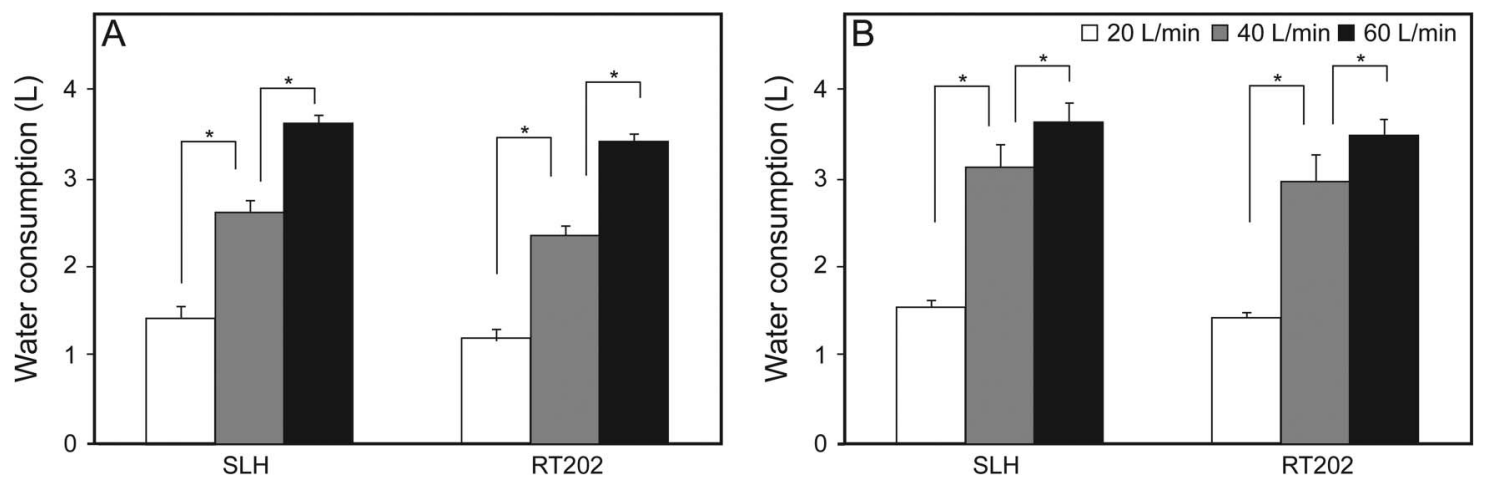

Fig. 4. Distilled water consumed after $24 \mathrm{~h}$ at high-flow nasal cannula flows of 20,40 , and $60 \mathrm{~L} / \mathrm{min}$. A: Ambient temperature set at $25^{\circ} \mathrm{C}$. B: Ambient temperature set at $20^{\circ} \mathrm{C} .{ }^{*}=P<.05$.

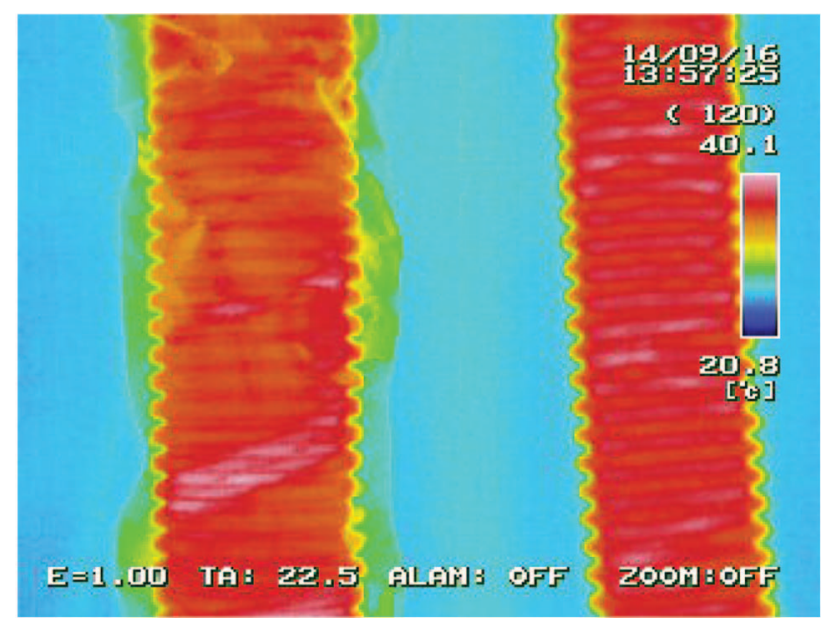

Fig. 5. Thermographic images of tested tubes, when ambient temperature was set at $20^{\circ} \mathrm{C}$. Left: SLH. Right: RT202. With the SLH, the image shows a zone of warm air between the sleeve and tube.

condensation when HFNC flow is high, and absolute humidity remains high at high HFNC flow.

When ambient temperature was set to $25^{\circ} \mathrm{C}$, condensation with the SLH was greater than with the RT202. In the SLH tube, the heater wire ends $18 \mathrm{~cm}$ from the distal end of the tube. In the RT202, the gap is $10 \mathrm{~cm}$. At the higher ambient temperature, it is fair to assume that condensation mostly occurred along these non-heated lengths of tubing and that the greater unheated length in the SLH resulted in more condensation. By contrast, at the lower ambient temperature (set to $20^{\circ} \mathrm{C}$ ), more condensation occurred with the RT202. Because the SLH tube is enveloped in a plastic sleeve, the air space between the sleeve tubing mitigated the cooling caused by the lower ambient air temperature. Thermographic imaging (Thermo GEAR G120EX, Nippon Avionics, Tokyo, Japan) showed a warm air zone between the sleeve and the tube (Fig. 5). This zone might decrease the temperature difference between the inside and outside of the SLH tube, thus effectively reducing the amount of condensation.
The amount of water in the tubing might be affected by the amount of vapor supplied from the humidifier (lesser or greater consumption of distilled water) and by the water contents in the gas leaving the nasal cannula. If water consumption were lower and humidification were poorer, less condensation would occur. We measured distilled water consumption for $24 \mathrm{~h}$ to confirm that both of the heated humidifiers had supplied adequate vapor. Theoretical consumption was calculated as follows: (absolute humidity at $\left.37^{\circ} \mathrm{C}\right) \times(\mathrm{HFNC}$ gas flow $) \times 24 \mathrm{~h}=44(\mathrm{mg} / \mathrm{L}) \times(\mathrm{HFNC}$ gas flow) $\times 1,440$ (min).

Theoretical 24-h distilled water consumption at 20, 40 , and $60 \mathrm{~L} / \mathrm{min}$ is $1,267,2,534$, and 3,802 $\mathrm{mL}$. Results show that actual water consumption at 20 and $40 \mathrm{~L} / \mathrm{min}$ with both types of tubes was close to the theoretical values.

When initially supplied, medical gas is usually cooler than $20^{\circ} \mathrm{C}$; therefore, we first measured flow with a pneumotachometer before turning on the heated humidifier. When the gas was subsequently warmed to $37^{\circ} \mathrm{C}$, the initial flows of 20,40 , and $60 \mathrm{~L} / \mathrm{min}$ increased to $21.2,42.3$, and $63.5 \mathrm{~L} / \mathrm{min}$. Water consumption also increased to 1,340 , 2,681 , and $4,022 \mathrm{~mL} / 24 \mathrm{~h}$. At flows of 20 and $40 \mathrm{~L} / \mathrm{min}$, actual water consumption of $1,399 \pm 164$ and $2,776 \pm 365 \mathrm{~mL}$ was similar to the theoretical values. When gas flow was $60 \mathrm{~L} / \mathrm{min}$, actual consumption was less than the theoretical value. At gas flows of 20,40 , and $60 \mathrm{~L} / \mathrm{min}$, with both types of tubes, the electrical output of the heated humidifier heater plates was confirmed using View850 software (Fisher \& Paykel, Auckland, New Zealand): At flows of 20 and $40 \mathrm{~L} / \mathrm{min}$, the output was $<100 \%$, and the temperatures at the outlet of the water reservoir and at the end of the inspiratory tubes were maintained at 37 and $40^{\circ} \mathrm{C}$; at $60 \mathrm{~L} / \mathrm{min}$, the output of heater plates was continuously $100 \%$, and the humidifier-outlet and tubeend temperatures were lower than set. It seems that the highest flow setting exceeded the capacity of the heated humidifier to deliver vapor: At $60 \mathrm{~L} / \mathrm{min}$, it seemed unable to deliver $44 \mathrm{mg} / \mathrm{L}$ of vapor. Consequently, the amount of 
condensation at $60 \mathrm{~L} / \mathrm{min}$ was $<3$ times the amount of condensation at $20 \mathrm{~L} / \mathrm{min}$. Since the consumption of distilled water at $60 \mathrm{~L} / \mathrm{min}$ was similar for the SLH and the RT202, differences in the amount of condensation were not due to different consumption of distilled water.

Although the results of this bench study cannot be directly applied to clinical situations, they do highlight a potential source of risk during HFNC therapy. Condensation in the inspiratory tube may cause problems besides vapor loss and inadequate humidification: the presence of moisture increases the risk of bacterial contamination. In addition, condensation may be blown into the nares of patients. When ambient temperature was set at $20^{\circ} \mathrm{C}$, more condensation occurred in the RT202. On the other hand, the RT202 delivered a fair amount of vapor, and this does not necessarily mean that the RT202 performs less capably than the SLH as an HFNC therapy gas delivery tube.

In conclusion, we investigated how ambient temperature, HFNC flow and the thermal characteristics of the inspiratory tube affected condensation in inspiratory tubes during HFNC therapy. There were differences in condensation depending on the length of exposed unheated tube and thermal insulation from the plastic sleeve. Apart from minor differences attributable to the thermal characteristics of the tubes, resulting in less effective humidification, more condensation occurred when ambient temperature was lower.

\section{REFERENCES}

1. Bolger C, Tufvesson E, Anderson SD, Devereux G, Ayres JG, Bjermer $\mathrm{L}$, et al. Effect of inspired air conditions on exercise-induced bronchoconstriction and urinary CC16 levels in athletes. J Appl Physiol 2011;111(4):1059-1065.

2. Miyamoto K, Nishimura M. Nasal dryness discomfort in individuals receiving dry oxygen via nasal cannula. Respir Care 2008;53(4):503-504.

3. Chanques G, Constantin JM, Sauter M, Jung B, Sebbane M, Verzilli D, et al. Discomfort associated with underhumidified high-flow oxygen therapy in critically ill patients. Intensive Care Med 2009; 35(6):996-1003.

4. de Paula LCS, Siqueira FC, Juliani RCTP, de Carvalho WB, Ceccon MEJR, Tannuri U. Post-extubation atelectasis in newborns with surgical diseases: a report of two cases involving the use of a high-flow nasal cannula. Rev Bras Ter Intensiva 2014;26(3):317-320.

5. Nishimura M. High flow nasal cannula oxygen therapy in adults. J Intensive Care 2015;3(1):15.

6. Chikata Y, Izawa M, Okuda N, Itagaki T, Nakataki E, Onodera M, et al. Humidification performances of two high flow nasal cannula devices: a bench study. Respir Care 2014;59(8):1186-1190.

7. Chikata Y, Imanaka H, Onishi Y, Ueta M, Nishimura M. Humidification during high-frequency oscillation ventilation is affected by ventilator circuit and ventilator setting. Paediatr Anaesth 2009;19(8): 779-783.

8. Nishida T, Nishimura M, Fujino Y, Mashimo T. Performance of heated humidifiers with a heated wire according to ventilator settings. J Aerosol Med 2001;14(1):43-51.

9. Branson R, Campbell RS, Chatburn RL. AARC clinical practice guideline: humidification during mechanical ventilation. Respir Care 1992;37(8):887-890. 